\title{
O IMPACTO DA POLÍTICA DE ASSISTÊNCIA ESTUDANTIL NO DESEMPENHO ACADÊMICO DOS(DAS) ESTUDANTES: A PERCEPÇÃO DOS MEMBROS DA CLAE DO IF BAIANO, CAMPUS SENHOR DO BONFIM E OS INDICADORES INSTITUCIONAIS
}

\author{
Adriano dos Santos Moraes ${ }^{1}$ \\ Jéssica Silva Almeida ${ }^{2}$ \\ Maria da Conceição Silva Almeida ${ }^{3}$
}

RESUMO: Esta pesquisa visa investigar o impacto da Política de Assistência Estudantil (PAE) no Instituto Federal Baiano, Campus Senhor do Bonfim no desempenho acadêmico dos estudantes beneficiários, a partir da percepção dos membros da Comissão Local de Assistência Estudantil e de indicadores institucionais. Utilizou-se uma abordagem qualitativa e os procedimentos técnicos empregados foram a pesquisa bibliográfica, documental, levantamentos de dados e pesquisa de campo (grupo focal). Os resultados alcançados pela pesquisa apontam a necessidade de aperfeiçoamento e fortalecimento do financiamento da PAE do IF Baiano, e a necessidade de realização de novos estudos.

Palavras-chave: Política Pública de Assistência Estudantil. Desempenho Acadêmico. 1651 Vulnerabilidade socioeconômica. Evasão escolar.

ABSTRACT: This research aims to investigate the impact of the Student Assistance Policy (PAE) at the Federal Institute of Bahia, Campus Senhor do Bonfim on the academic performance of beneficiary students, from the perception of the members of the Local Student Assistance Commission and institutional indicators. A qualitative approach was used and the technical procedures used were bibliographical research, documental research, data surveys and field research (focus group). The results achieved by the research point to the need to improve and strengthen the financing of the PAE of the IF Baiano, and the need to carry out new studies.

Keywords: Student Assistance Public Policy. Academic achievement. Socioeconomic vulnerability. School dropout.

\footnotetext{
' Mestre em Educação Profissional e Tecnológica (PROFEPT/IFBA). Especialista em Gestão Pública (Universidade Cândido Mendes - UCAM). Especialista em Direito Educacional e Graduado em Gestão Pública (Anhanguera UNIDERP, Técnico Administrativo em Educação, Instituição: Instituto Federal Baiano.

${ }^{2}$ Bacharel em Direito (UNEB) e Pós-graduada em Direito Constitucional Aplicado, Técnica Administrativa em Educação, Instituição: Instituto Federal Baiano.

${ }^{3}$ Mestranda no Programa de Mestrado Profissional Gestão e Tecnologia Aplicadas à Educação (GESTEC). Pós-graduada em Gestão Governamental - Especialização, pela Universidade do Estado da Bahia. Especialização em Estudos Linguísticos e Literários, pela Faculdade de Tecnologia de Valença. Graduada em Português e Literaturas de Língua Portuguesa, pela Universidade do Estado da Bahia.
} 


\section{INTRODUÇÃO}

No contexto da Educação Profissional e Tecnológica (EPT), as políticas de assistência estudantil cumprem com a finalidade de instrumentalizar os(as) estudantes com recursos básicos e viabilizar as condições materiais que possibilitem sua permanência e êxito acadêmico, abrangendo a demanda das camadas de baixa renda que ingressam na EPT, através do financiamento de despesas e do atendimento das mais diversas necessidades estudantis no decorrer do processo formativo desses e dessas estudantes.

Para Kowalski (2012) e Ramalho (2013), a assistência estudantil é a organização de serviços de apoio ou iniciativas voltadas para os(as) discentes em situação de vulnerabilidade socioeconômica, que busquem democratizar $o$ acesso ao ensino, assegurando as condições estruturantes para favorecer a permanência e sucesso acadêmico dos(as) estudantes.

Dessa maneira, as políticas de assistência estudantil compreendem ações que objetivam a superação das desigualdades de acesso, permanência e êxito do(a) aluno(a), por meio de programas de benefícios sociais e de acompanhamento, com vistas a contribuir para sua educação e formação. (KOWALSKI, 2012; RAMALHO, 2013).

Nessa linha, o pressuposto dessa pesquisa é de que é imperiosa e extremamente necessária a adoção de ações e programas assistenciais para mitigar os efeitos diretos e indiretos deletérios ocasionados pela desigualdade social e educacional brasileira, e para colaborar para um melhor desempenho acadêmico dos estudantes beneficiados por estas Políticas de Assistência Estudantil.

O problema da pesquisa é então apresentado na forma da seguinte pergunta: “ $A$ partir da percepção dos membros da Comissão Local de Assistência Estudantil e dos indicadores institucionais, em que medida a Política de Assistência Estudantil (PAE) no Instituto Federal Baiano, Campus Senhor do Bonfim impacta no desempenho acadêmico dos estudantes beneficiários?”.

Essa pesquisa é classificada como descritiva, possuindo natureza qualitativa, método dedutivo e os procedimentos técnicos empregados foram a pesquisa bibliográfica, documental e de campo, através da realização de grupo focal.

O objetivo geral da pesquisa é avaliar o impacto da Política de Assistência Estudantil (PAE) no Instituto Federal Baiano, Campus Senhor do Bonfim no desempenho acadêmico 
dos estudantes beneficiários, a partir da percepção dos membros da Comissão Local de Assistência Estudantil (CLAE), em consonância com os indicadores institucionais.

Para alcançar o objetivo geral, elegeu-se como objetivos específicos os seguintes: a) Investigar o histórico, princípios, diretrizes, normas legais e regulamentações da Política de Assistência Estudantil (PAE) no contexto do Instituto Federal Baiano, o que foi feito mediante pesquisa bibliográfica e documental; e, b) Apresentar os aspectos gerais sobre as competências, estrutura, composição e atribuições da Comissão Local de Assistência Estudantil do IF Baiano, Campus Senhor do Bonfim, o que se deu através de pesquisa documental e descritiva.

A pesquisa observou os requisitos éticos previstos na legislação vigente, seguindo os preceitos de anonimato, participação voluntária e confiabilidade, no intuito de resguardar os dados pessoais, socioeconômicos, profissionais e acadêmicos dos participantes, garantindo-lhes a dignidade da pessoa humana e o direito de interromper a sua participação na pesquisa a qualquer momento, sem precisar justificar a sua decisão, caso se sentissem constrangidos ou tivessem dificuldade em expor suas concepções e opiniões. (CONSELHO NACIONAL DE SAÚDE, 2012).

A fim de mitigar os riscos da pesquisa, o pesquisador tomou todas as providências e cautelas cabíveis para evitar e/ou reduzir efeitos e condições adversas que pudessem causar dano, considerando as características, o contexto do participante e a aprovação da pesquisa pelo Comitê de Ética em Pesquisa do Instituto Federal de Educação, Ciência e Tecnologia da Bahia (CEP-IFBA). (CONSELHO NACIONAL DE SAÚDE, 20I6).

Dada a necessidade de um melhor recorte e delimitação da pesquisa, na primeira seção discorremos sobre os aspectos gerais da Comissão Local de Assistência Estudantil do IF Baiano, Campus Senhor do Bonfim. Na segunda seção, apresentamos o percurso metodológico adotado, e, na seção subsequente, demostramos os resultados e discussão da pesquisa. Por fim, apresentamos na última seção algumas considerações sobre a temática.

Respeitado os limites dessa pesquisa, entendemos que ela demonstra o impacto positivo da Política de Assistência Estudantil na vida dos(das) estudantes, a partir dos dados e indicadores institucionais apresentados e da percepção da CLAE, uma vez que há evidências de que a PAE, na medida do que lhe é possível contribuir, ajuda a viabilizar as condições necessárias e os meios materiais básicos para a fruição mais plena do ambiente 
escolar, através da concessão dos diversos auxílios que compõem essa política, como auxílio moradia, transporte, creche, auxílio permanência, cópia e impressão, uniforme, material acadêmico e alimentação, dentre outros, o que tende a ajudar a diminuir os índices de evasão estudantil.

Os resultados alcançados pela pesquisa apontam a necessidade de aperfeiçoamento e fortalecimento do financiamento da PAE do IF Baiano, dada a importância dessa política no desideratum de superação dos obstáculos, impedimentos e barreiras ao desempenho acadêmico exitoso, considerando que a PAE tem contribuído, em certa medida, para que os(as) estudantes em vulnerabilidade socioeconômica percebam os meios materiais necessários ao seu bem estar biopsicossocial e acadêmico, colaborando assim para a permanência e êxito dos(das) estudantes beneficiados(as) por essa política pública e para o enfrentamento do fenômeno da evasão escolar, especialmente no atual cenário pandêmico.

Ademais, identificamos a necessidade de aprofundamento da pesquisa e da realização de novos estudos, principalmente quanto à permanência e à conclusão com êxito dos(das) estudantes beneficiados(as) pela PAE ao longo de seus percursos acadêmicos e suas trajetórias, e sobre a condição dos(das) estudantes egressos(as) que foram anteriormente beneficiados(as) pela PAE.

\section{ASPECTOS GERAIS DA COMISSÃO LOCAL DE ASSISTÊNCIA ESTUDANTIL DO IF BAIANO, CAMPUS SENHOR DO BONFIM.}

A Resolução no or, de 29 de janeiro de 2019, respaldada no Decreto no 7.234, de 19 de julho de 2oro, que dispõe sobre o PNAES, instituiu a Política de Assistência Estudantil do Instituto Federal Baiano (IF Baiano), que se constitui em um conjunto de princípios e diretrizes norteadores para o desenvolvimento de programas e linhas de ações que favoreçam a democratização do acesso, permanência e êxito do(da) discente durante seu processo formativo, "compreendida numa perspectiva de universalização do direito à educação e formação integral dos sujeitos, abrange todos os estudantes regularmente matriculados". (IF BAIANO, 2019, p. I). Esta resolução prevê a criação de órgãos colegiados, a saber: o Fórum Permanente da Assistência Estudantil ${ }^{4}$ e a Comissão Local de Assistência Estudantil (CLAE), que será apresentada adiante. (IF BAIANO, 2019).

\footnotetext{
Para obter mais informações sobre o Fórum Permanente da Assistência Estudantil e os Programas instituídos pela Política de Assistência Estudantil do IF Baiano, consulte a Resolução no or, de 29 de janeiro
} 
A CLAE deve ser composta, ao menos, da seguinte equipe multiprofissional: o(a) coordenador(a) de Assuntos Estudantis, um(a) assistente social, um(a) psicólogo(a), um pedagogo, um(a) nutricionista, um(a) outro(a) profissional da área de saúde, um(a) assistente de alunos, um(a) representante do setor financeiro, o(a)s presidentes dos Núcleos dos Programas de Assistência Estudantil, dois(duas) estudantes de níveis de ensino diversos e seus suplentes, sendo que os membros dessa Comissão serão indicados pela Direção Geral do Campus, exceto os(as) estudantes, que serão indicados(as) pelas representações de base. (IF BAIANO, 2019).

As atribuições gerais da CLAE estão previstas no art. I4 da Resolução noo or, de 29 de janeiro de 2019, e envolvem a divulgação das ações da Assistência Estudantil na perspectiva de consolidá-la como política institucional; o acompanhamento e avaliação dos programas, projetos e ações desenvolvidos no âmbito da Política de Assistência Estudantil do Campus; a criação dos núcleos assistenciais que lidarão com os Programas; e, a prestação dos devidos esclarecimentos sobre os programas e ações da Assistência Estudantil. (IF BAIANO, 2019).

No que se refere à implementação e gestão de recursos financeiros da Política de Assistência Estudantil, também é responsabilidade da CLAE a realização de reuniões, anuais ou quando necessário for, para apresentação de sugestões à Direção Geral, para efeito de utilização dos recursos da Assistência Estudantil; o envio de relatório contendo as informações solicitadas pela Diretoria de Assuntos Estudantis, ao final de cada processo de seleção para o Paise; e o acompanhamento da aplicação dos recursos financeiros da Assistência Estudantil. (IF BAIANO, 2019).

Também, incumbe à Comissão Local de Assistência Estudantil a designação de representante para participação da realização de diagnóstico e emissão de parecer dos serviços prestados pelos refeitórios e sobre as condições de infraestrutura das residências estudantis; a elaboração de relatório anual referente à implementação dos programas, e envio deste para a Coordenação Geral de Assistência Estudantil, com cópia para a Diretoria de Assuntos Estudantis; e, a colaboração com a DAE na análise e emissão de parecer sobre os casos omissos. (IF BAIANO, 2019).

de 2019, disponível em: http://www.ifbaiano.edu.br/unidades/itapetinga/files/2011/o5/Resolução-oi-2019Aprova-Pol\%C3\%ADtica-de-Assist\%C3\%AAncia-Estudantil-Processo-n\%C2\%BA-23327.002530-2018.42.pdf. 
A avaliação da Política de Assistência Estudantil do IF Baiano deverá ser contínua e processual, realizada por todos os atores envolvidos e coordenada pela Coordenação Geral de Assistência Estudantil. As Comissões Locais de Assistência Estudantil deverão elaborar um relatório anual, que será encaminhado à Coordenação Geral de Assistência Estudantil, com cópia para a Direção Geral do Campus e Diretoria de Assuntos Estudantis, para a avaliação da execução da PAE, sendo que, com base nos relatórios acima citados, sempre que for constatada a pertinência, a PAE poderá ser revisada pelo Fórum Permanente de Assistência Estudantil, que será convocado: I - pela Diretoria de Assuntos Estudantis; ou II - por dois terços dos membros do Fórum. Havendo necessidade de alteração ou revisão do seu conteúdo, a PAE deve ser submetida à apreciação do Conselho Superior do IF Baiano, por solicitação da Pró-Reitoria de Ensino. (IF BAIANO, 2019).

Uma gestão eficiente é necessária para que a Política de Assistência Estudantil alcance seu objetivo de contribuir para diminuir as disparidades sociais decorrentes das distintas posições que os estudantes se encontram, notadamente em termos econômicos e sociais, visando estimular a criatividade, a reflexão crítica, as atividades e os intercâmbios cultural, esportivo, artístico, político, científico e tecnológico dos estudantes beneficiados, sendo que a Comissão Local de Assistência Estudantil exerce um importante papel nesse processo.

\section{PERCURSO METODOLÓGICO}

O lócus da pesquisa foi o Instituto Federal Baiano (IF Baiano), Campus Senhor do Bonfim, que está situado dentro do Território de Identidade Piemonte Norte do Itapicuru, e que foi uma das unidades das antigas Escolas Agrotécnicas Federais (EAFs) incorporadas à Rede Federal de Educação Profissional e Tecnológica, através da Lei no Ir.892, de 29 de dezembro de 2008. (BRASIL, 2008)

Segundo o Plano de Desenvolvimento Institucional (PDI) do IF Baiano, o Campus Senhor do Bonfim atende a um total de 1.623 alunos(as) cujas matrículas estão distribuídas entre os cursos técnicos na forma integrada (449), cursos técnicos na forma subsequente (261), EaD (683) e cursos superiores (230). (IF BAIANO, 2015).

Em relação aos participantes da pesquisa, foram incluídos aqueles(as) que se apresentaram como voluntários(as), desde que contemplassem o critério de ser membro da 
Comissão Local de Assistência Estudantil (CLAE) do IF Baiano, Campus Senhor do Bonfim, sendo excluídos da pesquisa, por sua vez, aqueles que não integrassem essa comissão.

O Grupo Focal (GF) foi realizado através do serviço de conferência web utilizando o software Skype (que permite a comunicação pela Internet através de conexões de voz e vídeo), em face dos efeitos da pandemia do coronavírus (Sars-CoV-2) na realidade social prevalecente no ano de 2020 , especialmente em razão do fechamento completo de diversos espaços físicos e da restrição à circulação e aglomerações de pessoas.

O GF foi realizado com os membros da Comissão Local de Assistência Estudantil do IF Baiano (CLAE), Campus Senhor do Bonfim, que é composta por doze integrantes, sendo que dez deles participaram. Foram realizadas duas sessões: I $^{\underline{a}}$ Sessão - Roda de conversa sobre a temática da Política de Assistência Estudantil, rapport inicial (2I/10/2020); e, $2^{\underline{a}}$ Sessão - Encerramento (26/10/2020), com tempo médio de 50 min. e $40 \mathrm{~min}$, respectivamente. As falas dos participantes do GF foram gravadas e transcritas para facilitar a análise através de recurso de transcrição disponível na plataforma Youtube ${ }^{6}$ e as questões norteadoras que foram utilizadas durante o GF foram as seguintes: I) Iniciativas de Capacitação da CLAE, 2) Previsão orçamentária e execução dos recursos da PAE, 3) Implantação e procedimentos de operacionalização da $\mathrm{PAE}, 4)$ Instrumentos de Avaliação da PAE, 5) Instrumentos de Controle da PAE, 6) Conhecimento e participação do segmento Docente e Técnico Administrativo na PAE, 7) Enfrentamento às dificuldades e vulnerabilidade dos estudantes beneficiários da PAE, 8) Percepção da CLAE sobre a relação entre os índices de Evasão e a permanência e êxito estudantil dos beneficiários da PAE, 9) Meios de divulgação da PAE para a comunidade interna e externa.

Durante as sessões, foi mantida a atenção máxima aos depoimentos dos participantes que expressaram aspectos que interferiam na implementação da PAE do IF Baiano, como

\footnotetext{
${ }^{5}$ A web conferência do software Skype é um serviço de comunicação e colaboração que promove encontros virtuais entre dois ou mais participantes. É um serviço que leva para o ambiente web os recursos próprios de uma conferência que use vídeo e áudio combinados, porém, há outras funcionalidades de interação instantânea e colaborativa como chat, bloco de notas, visualização compartilhada de imagens, arquivos ou mesmo da tela de um computador remoto. $\mathrm{O}$ serviço possibilita que, mesmo distantes geograficamente, os participantes compartilhem áudio, vídeo, texto, imagens e etc. (SKYPE, 2020).

${ }^{6}$ Segundo Dantas (2020) “o Youtube utiliza o formato 'Macromedia Flash' para reproduzir os conteúdos, além de permitir que usuários coloquem os vídeos em seus blogs e sites pessoais”, sendo que a sua principal função é permitir que os usuários carreguem, assistam e compartilhem vídeos em formato digital, além de disponibilizar recursos como transcrição e legendas de vídeos.
} 
também os fatores que causaram tensões ou dificuldades para a sua operacionalização, execução e gestão. $\mathrm{O}$ moderador deixou os(as) participantes da pesquisa confortáveis, encorajando-os(as) para que expressassem autonomamente suas concepções sobre a temática em discussão, buscando falar pouco e ouvir mais, e em alguns momentos fazer intervenções, quando necessário, para manter o debate focalizado e em consonância com a temática.

\section{I Metodologia de análise dos dados e informações do grupo focal}

$\mathrm{Na}$ análise dos conteúdos dos grupos focais, enfatiza-se a necessidade de utilização, nesse processo, de um método capaz de apreender opiniões solidamente mantidas e frequentemente expressas (GOMES; BARBOSA, 1999). No caso específico de pesquisas avaliativas, a análise sistemática e cuidadosa das discussões vai fornecer pistas e insights sobre como um produto, serviço ou plano é percebido (CARLINI-COTRIM, 1996). Entre as técnicas mais empregadas nessa fase, destacam-se a análise de conteúdo e a análise do discurso, sendo a técnica utilizada para análise dos dados no caso específico desta pesquisa a análise de conteúdo, proposta por Bardin (2006, p. 47), que a define como:

Um conjunto de técnicas de análise das comunicações visando a obter, por procedimentos sistemáticos e objetivos de descrição do conteúdo das mensagens, indicadores (quantitativos ou não) que permitam a inferência de conhecimentos relativos às condições de produção/recepção (variáveis inferidas) destas mensagens. (BARDIN, 2006, p. 47).

Godoy (1995) afirma que a análise de conteúdo, segundo a perspectiva de Bardin (2006), consiste em uma técnica metodológica que se pode aplicar em discursos diversos e a todas as formas de comunicação, seja qual for à natureza do seu suporte. Nessa análise, o pesquisador busca compreender as características, estruturas ou modelos que estão por trás dos fragmentos de mensagens tornados em consideração. O esforço do analista é, então, duplo: entender o sentido da comunicação, como se fosse o receptor normal, e, principalmente, desviar o olhar, buscando outra significação, outra mensagem, passível de se enxergar por meio ou ao lado da primeira. Optou-se por elencar as etapas da técnica segundo Bardin (2006), que as organiza em três fases: I) pré-análise, 2) exploração do material e 3) tratamento dos resultados, inferência e interpretação.

A pré-análise é a fase em que se organiza o material a ser analisado com o objetivo de torná-lo operacional, sistematizando as ideias iniciais. Trata-se da organização 
propriamente dita por meio de quatro etapas: (a) leitura flutuante, que é o estabelecimento de contato com os documentos da coleta de dados, momento em que se começa a conhecer o texto; (b) escolha dos documentos, que consiste na demarcação do que será analisado; (c) formulação das hipóteses e dos objetivos; (d) referenciação dos índices e elaboração de indicadores, que envolve a determinação de indicadores por meio de recortes de texto nos documentos de análise (BARDIN, 2006).

A exploração do material constitui a segunda fase, que consiste na exploração do material com a definição de categorias (sistemas de codificação) e a identificação das unidades de registro (unidade de significação a codificar corresponde ao segmento de conteúdo a considerar como unidade base, visando à categorização e à contagem frequencial) e das unidades de contexto nos documentos (unidade de compreensão para codificar a unidade de registro que corresponde ao segmento da mensagem, a fim de compreender a significação exata da unidade de registro). A exploração do material consiste numa etapa importante, porque vai possibilitar ou não a riqueza das interpretações e inferências. Esta é a fase da descrição analítica, a qual diz respeito ao corpus (qualquer material textual coletado) submetido a um estudo aprofundado, orientado pelas hipóteses e referenciais teóricos. Dessa forma, a codificação, a classificação e a categorização são básicas nesta fase (BARDIN, 2006).

Destaca-se que a categorização foi realizada através da análise temática, possibilidade indicada por Bardin (2006) como eficaz para aplicação dos discursos diretos e simples. A autora também enfatiza a importância de se considerar em pesquisas qualitativas a subjetividade da fala e como ela está carregada dos sistemas de pensamentos, processos cognitivos, valores, representações, emoções e afetividade. Assim, a opção da categorização organizada por tema é a alternativa mais pertinente à execução desta pesquisa. Para Bardin:

\footnotetext{
O tema é geralmente utilizado como unidade de registro para estudar motivações de opiniões, de atitudes, de valores, de crenças, de tendências etc. As respostas a questões abertas, as entrevistas (não diretivas ou mais estruturadas) individuais ou de grupo, de inquérito ou de psicoterapia, os protocolos de testes, as reuniões de grupo, os psicodramas, as comunicações de massa etc., podem ser, e frequentemente são analisados tendo o tema por base. (2006, p. 135).
}

A terceira fase diz respeito ao tratamento dos resultados, inferência e interpretação. Essa etapa é destinada ao tratamento dos resultados; ocorre nela a condensação e o 
destaque das informações para análise, culminando nas interpretações inferenciais; é o momento da intuição, da análise reflexiva e crítica (BARDIN, 2006).

Tendo em vista as diferentes fases da análise de conteúdo proposta por Bardin (2006), destacam-se as dimensões da codificação e categorização que possibilitam e facilitam as interpretações e as inferências. No que tange à codificação, "corresponde a uma transformação - efectuada (sic) segundo regras precisas - dos dados brutos do texto, transformação esta que, por recorte, agregação e enumeração, permite atingir uma representação do conteúdo, ou da sua expressão" (Ibidem, p. I03). Após a codificação, segue-se para a categorização, a qual consiste na classificação de elementos constitutivos de um conjunto, por diferenciação e, seguidamente, por reagrupamento segundo o gênero (analogia), com os critérios previamente definidos. As categorias, "são rubricas ou classes, as quais reúnem um grupo de elementos sob um título genérico, agrupamento esse efectuado (sic) em razão dos caracteres comuns destes elementos”. (Ibidem, p. II7).

Cabe salientar que tais etapas envolvem diversos simbolismos que precisam ser decodificados. Para tanto, o pesquisador precisa fazer um esforço para desvendar o conteúdo latente, como refere Triviños (1987, p. 162). Nesse sentido, a análise contextual e histórica é de grande valia (BATESON, 2000; THOMPSON, 1995), além da criatividade, intuição e crítica (BARDIN, 2006; THOMPSON, 1995).

A análise e interpretação das informações coletadas foram estruturadas a partir do que preconiza Bardin (2006) sobre a questão, não sendo o objetivo desta pesquisa descrever por completo o conteúdo do GF, mas a partir do tratamento sistemático desses dados, apresentar o que ele pode 'dizer' a respeito do tema proposto.

As categorias primárias (unidades de registro) representam o conjunto das principais indicações temáticas emergidas das discussões, previamente transcritas, separadas em parágrafos e alinhadas ao referencial teórico. Essas ideias agrupadas tematicamente formam as categorias secundárias, que mais uma vez passam por um processo de revisão temática, culminando nas categorias finais. A nomenclatura das categorias foi uma opção assumida nesta pesquisa, visto não haver regras para este fim, no entanto todas as fases de análise estão pautadas nas referências mencionadas de Bardin (2006).

Analisando as transcrições das falas dos participantes do GF, foi possível estabelecer ligações temáticas e associações teóricas que resultaram em categorias primárias. Para 
melhor compreensão e visando facilitar o processo de análise, algumas partes das falas transcritas consideradas as mais relevantes durante o GF, à luz da teoria estudada e das inferências resultantes delas, são analisadas na seção subsequente.

Ainda, no quadro abaixo apresenta-se, de forma sintética, a formação das categorias.

Quadro I - Síntese da formação das categorias.

\begin{tabular}{|c|c|c|c|}
\hline $\mathbf{N}^{\circ}$ & $\begin{array}{l}\text { CATEGORIAS } \\
\text { PRIMÁRIAS }\end{array}$ & CATEGORIAS SECUNDÁRIAS & CATEGORIAS FINAIS \\
\hline I & $\begin{array}{l}\text { Previsão orçamentária } \\
\text { dos recursos da PAE }\end{array}$ & $\begin{array}{l}\text { Implantação, procedimentos e } \\
\text { aperfeiçoamento da PAE }\end{array}$ & \multirow{4}{*}{$\begin{array}{l}\text { Aspectos da Gestão e de } \\
\text { Difusão de Informação sobre } \\
\text { a Política de Assistência } \\
\text { Estudantil do IF Baiano }\end{array}$} \\
\hline 2 & $\begin{array}{l}\text { Execução dos recursos } \\
\text { da PAE }\end{array}$ & & \\
\hline 3 & $\begin{array}{l}\text { Meios de divulgação da } \\
\text { PAE para a comunidade } \\
\text { interna }\end{array}$ & \multirow[b]{2}{*}{$\begin{array}{c}\text { Transparência e acesso à Informação sobre } \\
\text { a PAE }\end{array}$} & \\
\hline 4 & $\begin{array}{l}\text { Meios de divulgação da } \\
\text { PAE para a comunidade } \\
\text { externa }\end{array}$ & & \\
\hline 5 & $\begin{array}{c}\text { Enfrentamento às } \\
\text { dificuldades e } \\
\text { vulnerabilidade dos(das) } \\
\text { estudantes } \\
\text { beneficiários(as) da PAE }\end{array}$ & \multirow[b]{2}{*}{$\begin{array}{l}\text { Vulnerabilidade, índices de evasão e } \\
\text { aspectos da permanência e êxito acadêmico } \\
\text { dos beneficiários da PAE }\end{array}$} & \multirow[b]{2}{*}{$\begin{array}{c}\text { Vulnerabilidade e } \\
\text { Desempenho Acadêmico do } \\
\text { estudantes beneficiários da } \\
\text { PAE }\end{array}$} \\
\hline 6 & $\begin{array}{l}\text { Percepção da CLAE } \\
\text { sobre a relação entre os } \\
\text { índices de Evasão e a } \\
\text { permanência e êxito } \\
\text { estudantil dos } \\
\text { beneficiários da PAE }\end{array}$ & & \\
\hline
\end{tabular}

Fonte: Elaboração própria do autor. 
$\mathrm{Na}$ seção subsequente, apresentamos os resultados e discussões relativos ao grupo focal realizado com a CLAE do IF Baiano, Campus Senhor do Bonfim.

\section{RESULTADOS E DISCUSSÕES}

A aplicação da técnica do GF mostrou-se satisfatória na coleta de informações, pois possibilitou conhecer os diversos aspectos que marcaram a percepção dos membros da Comissão Local de Assistência Estudantil do Instituto Federal Baiano, Campus Senhor do Bonfim, sobre à Política de Assistência Estudantil adotada pelo Instituto, especialmente no que se refere às iniciativas de capacitação, previsão orçamentária e execução dos recursos, implantação e procedimentos de operacionalização, avaliação e controle, e em relação ao enfrentamento às dificuldades e à condição de vulnerabilidade dos(das) estudantes, à percepção dos membros da CLAE sobre o impacto dessa política nos índices de desempenho acadêmico, e quanto aos meios de divulgação da PAE para a comunidade interna e externa.

Entendemos ser possível fazer algumas inferências sobre os resultados alcançados. Desta forma, sobre a categoria final 'Aspectos da Gestão e de Difusão de Informação sobre a Política de Assistência Estudantil do IF Baiano', resultante das categorias secundárias 'Implantação, procedimentos e aperfeiçoamento da PAE' e 'Transparência e acesso à Informação sobre a PAE', temos relacionada a ela as seguintes categorias primárias: 'Previsão orçamentária dos recursos da PAE, 'Execução dos recursos da PAE', 'Meios de divulgação da PAE para a comunidade interna' e 'Meios de divulgação da PAE para a comunidade externa'.

No que se refere às categorias primárias: 'Previsão orçamentária dos recursos da PAE' e 'Execução dos recursos da PAE', cabe trazer à atenção algumas informações sobre créditos orçamentários e execução de recursos financeiros da Política de Assistência Estudantil, disponíveis no Relatório de Gestão - Exercício 2019 do IF Baiano, que aponta que as despesas de custeio do Instituto relativa à assistência direta ao estudante na forma de bolsas, auxílios financeiros para o desenvolvimento de estudos e pesquisas, fornecimento de alimentação entre outros, somou $\mathrm{R}$ II,5 milhões em 2019. (IF BAIANO, 2020)

Entretanto, na comparação do Paise dos anos de 2018 e 2019, temos no ano de 2018 o montante de $\mathrm{R} \$ 6.198 .347$,oo, o qual foi reduzido para o valor de $\mathrm{R} \$ 4.081 .592,00$, no ano de 2019, sendo que os valores investidos no Auxílio Eventual por tipo foram os seguintes: 
Exames médicos - $\mathrm{R} \$ 4.270,00$, Exames odontológicos - $\mathrm{R} \$ 60,00$, Acompanhamento psicoterapêutico - R\$ I.88o,oo, Aquisição de óculos de grau - $\mathrm{R} \$ 48.624,05$, Tratamento dentário - R \$ I0.335,00, Compra de cama e colchão - R \$ I.530,00, e Outras demandas - R\$ 4.038,00. O número de estudantes atendidos(as) nos demais programas foi: Auxílios eventuais - 206, Residência estudantil - 746, Alimentação Estudantil - 6.239, Propac - II3, Pincel - 169, PRÓ-SAÚDE - 4.397 e Proap - 2.222. (IF BAIANO, 2020)

Nesse contexto, os membros da CLAE do IF Baiano, Campus Senhor do Bonfim, expressaram uma séria preocupação com os reiterados e sucessivos cortes orçamentários e financeiros que a Política de Assistência Estudantil tem sofrido nos últimos anos, conforme podemos perceber nas seguintes declarações:

"Sobre a questão orçamentária, como eu participo há alguns anos, é... tem diminuído!"

"[...] tem diminuído o recurso, e [...] como o auxílio tem diminuído, a gente sempre fica naquela questão: "Diminuir um pouco do valor para atingir mais pessoas, ou manter determinado valor e atingir menos pessoas?" Aí, isso sempre gera algumas discussões na Comissão [da CLAE] em relação a isso, porque às vezes também o valor fica tão baixo que até que ponto aquilo também é um auxílio, né?... que vai ser realmente efetivo?

"[...] sempre fica essa discussão de que... de "fazer muito" com esse "pouco" que.. a cada vez mais vem diminuindo, né?"

"É... até pela própria seleção que a gente faz [...] pela pouca quantidade de contemplados, né, que a gente oferece, pelo recurso, né, que é limitado, a gente percebe o quanto de pessoas que ficam de fora [...]"

"[...] é... que não consegue atender a todo mundo, por causa do recurso limitado, né?”

“[...] os próprios "documentos" mostram, que diminuiu!"

"[...] então é uma situação preocupante... como usar da melhor forma o tanto de recursos e pra ter um mínimo de danos".

"Em 2019, foi mais vulnerável, por conta dos cortes orçamentários, precisando reduzir a quantidade de beneficiários. Em 2020, por conta da pandemia as regras foram impostas pela minuta estabelecida pela Reitoria, as modificações para atender as necessidades locais dos alunos(as) que não foram incluídos, não puderam ser incluídas, estas foram observadas pelo próprio Centro acadêmico de representação estudantil, Grêmio estudantil e CLAE...”

Sobre a utilização dos recursos financeiros da PAE no período da pandemia da COVID-I9, os membros da CLAE disseram que:

"Em 2019, o recurso foi utilizado para pagamento dos auxílios do Paise. Em 2020, o recurso está sendo para pagamento do auxílio emergencial."

"A gente teve agora, por conta da pandemia, até uma folga, digamos assim, né, que pode contemplar este número de pessoas, mas no Paise, por exemplo, a gente não contemplaria todos esses(as) alunos(as).” 
"Se fosse... se tivesse no "presencial" [ensino] com aqueles auxílios lá: permanência, moradia, creche e alimentação [não daria para] contemplar todos, que ainda é pouco, né!”

"Em 2019, foi executado de forma eficiente [os recursos da PAE], apesar do contingenciamento. Em 2020 está sendo remanejado para os auxílios que surgiram com a pandemia."

"Financeiramente falando, enquanto recurso para alunos(as) [durante a Pandemia], foi o auxílio emergencial e o auxílio digital extraordinário, né, além, é claro, do os kits alimentícios do PNAE”.

As declarações supracitadas se alinham ao fato de que, das despesas com custeio (despesas correntes) do IF Baiano, o grupo custeio representou 22\% das despesas em 2019, no qual observou-se uma variação de $1,58 \%$ em relação a 2018 , onde os cinco elementos de despesa de maior impacto no total de gastos com custeios (locação de mão de obra, outros serviços de Pessoa Jurídica, auxílio-alimentação, material de consumo e auxílio financeiro a estudantes) representaram $83 \%$ do total, mas, com redução de $10 \%$ nas despesas com outros serviços de PJ; redução de $15,4 \%$ nas despesas com material de consumo; e redução de $31,4 \%$ nas despesas com o auxílio financeiro a estudantes (IF BAIANO, 2020). Tal situação de restrição orçamentária e de corte de recursos financeiros tende a implicar na diminuição do valor dos auxílios pagos aos(às) estudantes e em um número cada vez menor de contemplados(as), conforme percebido pelos integrantes da CLAE do IF Baiano, Campus Senhor do Bonfim.

No que concerne às categorias primárias 'Meios de divulgação da PAE para a comunidade interna' e 'Meios de divulgação da PAE para a comunidade externa', os participantes do GF declararam o seguinte:

"[...] quando a gente vai fazer a divulgação dos processos nas salas: a gente sempre dá uma atenção maior aos iniciantes, né, a quem está ingressando agora, explicando mais detalhadamente."

“[...] quando a pessoa já participou de um processo, normalmente não existem grandes modificações de um ano para outro, né, ele se repete - geralmente as mudanças são pequenas."

"[...] para quem está iniciando é muita informação porque são muitos documentos, muitas exigências, né, para participar."

"[...] dos processos que eu participei, foi por divulgação em sala de aula, em todas as turmas. Ia lá... e fazia... tinha fixação, a fixação dos processos nos murais... é do edital nos murais, com a data, com tudo... e tinha lá no site de IF Baiano também."

"Teve um ano que também teve a produção de vídeo também, explicando sobre o processo."

"Eu tinha conhecimento superficial, como eu já disse do funcionamento do Paise, mas aí quando veio essa de CLAE também, aí depois eu vim 'lilicando' 
[persistindo], né: “Ah! É tipo Comissão do Paise, é tipo uma Assistência Estudantil como em tal o lugar, e aí foi dando para ter uma visão assim do que realmente se tratava!"

“[...] lá logo nos primeiros semestres era horrível a comunicação, horrível mesmo!"

“[...] eu percebi uma melhora muito boa, sabe?, nesses últimos anos, um ano, um ano e meio... um ano, mais ou menos, eu percebi uma melhora na divulgação, né?"

“Teve Assistente [Social] lá que foi nas salas, falou... todos os detalhes de forma resumida, né? Porque [...] antigamente era muito assim: "Tem o edital sobre as “assistências" ... vão no site e procurem!" Ai, quando você é novato, e você vai atrás de edital, aparece um monte e para você entender esse Edital é outro processo. Aí, tinha gente que desistia, até porque não tinha paciência, sabe?... além de toda a documentação, mesmo pessoas que estavam precisando. Mas aí depois, quando o pessoal começou a ir na sala, né?... e eu lembro também da contribuição nessa nova galera aí da "assistência" é [...] então aí, os alunos(as)... eles começaram a se sentir mais à vontade, e a estar mais a par de todo o processo, entendeu?... mesmo concordando, ou não, com alguns resultados, mas graças a Deus e graças ao trabalho [da Comissão], essa divulgação melhorou."

"[...] "teve" o "Insta", "teve" o Facebook, "teve" os grupos [de WhatsApp], o pessoal também do Centro Acadêmico tem ajudado, né?"

"Então, em termos de divulgação, melhorou bastante!"

Quanto à disseminação de conhecimento e acesso à informação sobre a PAE do IF Baiano durante a suspensão das atividades presenciais em razão da Pandemia da COVID19, os membros da CLAE disseram que:

“[...] Nesta Pandemia, eu acho que teve um esforço muito positivo também no sentido de divulgação, né?”

“[...] a gente sempre busca explicar, de sala em sala... esse ano, mesmo com a pandemia, eu fiz o processo de divulgação em todas as salas... Aí depois veio a Pandemia e não pode ter o Paise, mas a divulgação foi feita!”

"Hoje, em tempos de pandemia, a gente tem usado muito dos grupos de WhatsApp, né, Instagram... o principal meio "tá" sendo o.... site institucional, né? E sempre que demanda uma resposta mais imediata, a gente têm utilizado lives."

"Eu não vejo como suficiente [o acesso à informação sobre a PAE], porque nem todos os(as) alunos(as) estão tendo acesso, tem muitos(as) alunos(as) que ainda não têm acesso à internet, por exemplo".

"Ainda assim, objetivamente falando, a gente tem alcançado boa parte dos nossos(as) alunos(as), né, mas não é suficiente.... eu acho que a gente não contempla a todos, com os meios que estamos tendo acesso agora!"

[...] talvez se houvesse um E-book com as principais dúvidas... algum tipo disso.

“Ou se houvesse... eu já vi que em outros ProfEPT's, eles fizeram algum tipo de aplicativo que deixava mais enxuta essas informações para os(as) alunos(as) sobre os auxílios e os critérios, talvez assim... é o que eu penso no momento..."

“Não, que eu saiba não!” [sobre conhecer algum App usado para divulgação da Assistência Estudantil no IF Baiano]. 
“Que eu saiba, também não!” [sobre conhecer algum App usado para divulgação da Assistência Estudantil no IF Baiano].

Nota-se que os membros da CLAE têm observado uma melhoria nos métodos de divulgação da Política de Assistência Estudantil, mas que os meios de divulgação, em geral, estão restritos à divulgação dos processos de seleção em sala de aula e ao uso de mídias sociais, a exemplo do Instagram, Facebook e de grupos de WhatsApp, site, e e-mail institucional do Campus, embora a CLAE tenha experimentado o uso de vídeos informativos sobre a PAE em determinada ocasião específica.

Alguns membros da CLAE relataram sobre a viabilidade da utilização de um e-book ou de um aplicativo para divulgação da PAE, mas ocorre que, por questões de ordem burocrática e administrativa da Instituição, o atendimento da demanda de desenvolvimento de um aplicativo adequado e útil necessitaria da atuação direta do setor de Tecnologia da Informação (TI) do Campus, o que não foi possível obter no presente momento, pela sobrecarga de trabalho desse setor.

Os integrantes da CLAE relataram também a experiência do projeto intitulado: CAEntrenós: estreitando os laços entre a CAE e os estudantes, que abrange a comunidade interna do IF Baiano, Campus Senhor do Bonfim, conforme segue:

"Nós fizemos... elaboramos uma proposta de desenvolvemos, por dois meses, se eu não me engano, um projeto intitulado: “CAE entre nós!”, né? Esse projeto, ele "tava" na mesma sala virtual [...] servidores da CLAE com os(as) alunos(as) de cada série... então a gente acessou todas as séries, evidentemente que com um número muito reduzido de cada série, mas passando um pouco dessa estrutura da CAE,... qual era o nosso papel - que deveríamos fazer, e como eles teriam acesso onde precisassem".

Segundo informado pela Coordenação de Assistência ao Educando (CAE) do Campus, o projeto CAEntre nós! tem como objetivo principal possibilitar um espaço de aproximação entre a CAE e os(as) estudantes do IF Baiano, Campus Senhor do Bonfim, durante o período de Pandemia da COVID-ı9, buscando investigar temáticas e metodologias para que a CAE possa realizar ações virtuais na área da saúde, como o projeto Saúde em Foco e outras intervenções, visando o bem-estar dos(das) discentes durante o período de isolamento social, através de encontros realizados via plataforma virtual, conforme cronograma elaborado pela equipe. Percebe-se que o projeto CAEntre nós! pode ser extremamente útil para a promoção de um espaço de escuta para os(as) 
estudantes, permitindo-lhes relatar aspectos de sua saúde física, mental e psicológica, e de sua relação com os estudos e com o convívio familiar.

No que se refere à categoria final Vulnerabilidade e Desempenho Acadêmico dos estudantes beneficiários da PAE, resultante da categoria secundária Vulnerabilidade, índices de evasão e aspectos da permanência e êxito acadêmico dos beneficiários da PAE, temos atrelada a ela as seguintes categorias primárias: Enfrentamento às dificuldades e vulnerabilidade dos(das) estudantes beneficiários(as) da PAE e Percepção da CLAE sobre a relação entre os indices de Evasão e a permanência e êxito estudantil dos beneficiários da PAE.

Nesse sentido, aspectos da condição de vulnerabilidade e algumas das dificuldades vivenciadas pelos (as) estudantes beneficiários(as) da Assistência Estudantil do IF Baiano, Campus Senhor do Bonfim foram apresentadas na categoria primária denominada: 'Enfrentamento às dificuldades e vulnerabilidade dos(das) estudantes beneficiários(as) da PAE':

"[...] sempre quando vem a parte dos recursos, por exemplo, das pessoas que... que entram com recurso, porque se sentiram injustiçadas, por que também estão em uma situação de vulnerabilidade, né? E aí, é [...] a gente tem essa.. tipo, essa situação..."

“[...] Então, só por isso já se percebe que é um contingente grande de pessoas [estudantes na condição de vulnerabilidade]!”

“[...] tinha algumas situações que fica a cargo da avaliação da Assistente Social, e nas próprias visitas que a gente faz é in loco, de alguns(mas) estudantes, né,... eu já participei de algumas visitas nas casas, e tal... só para fazer entrevista com a família...”

"É, eu acredito que seja bastante, né [estudantes na condição de vulnerabilidade]?”

"Sobre a vulnerabilidade dos(das) estudantes... ali, a gente não consegue alcançar todos os(as) estudantes que estão em situação de vulnerabilidade!”

"O Paise do ano passado foi prova disso, porque "[...] ficávamos "batendo cabeça" [...] todos os que estavam na lista precisavam e os que tinham ficado de fora, precisavam também! Como era que a gente ia fazer? E, os meninos "botando" recursos..."

“[...] teve caso de pessoas que é... deixaram de ser contempladas, que recebiam auxílio-moradia, e que sem esse auxílio-moradia iam acabar saindo do IF Baiano, porque não tinha como estudar - morando na cidade não tinha como pagar aluguel! E, não tinham como cursar morando na própria cidade dela!"

"Com certeza! [quanto à existência de muitos(as) alunos(as) na condição de vulnerabilidade]. Numa pesquisa empírica, digamos assim, né?"

"Nas conversas de bastidores que a gente tem com os(as) alunos(as).... a gente tem alunos(as) que vêm de mesorregiões que não são tão próximas! Nós temos alunos(as) de Várzea da Roça, Várzea do Poço, né? Alunos(as) que não são próximos... Então, eles têm que fixar residência... Geralmente eles não podem fixar residência no Centro, porque as casas no Centro são caras, mesmo eles alugando em grupo, né? Então, tem toda uma questão de vivência que esses 
sujeitos precisam construir de maturidade... de tantas coisas, porque dividir espaço não é fácil, né? Deixar toda uma estrutura que você tem na sua casa para vir para aqui... para Senhor do Bonfim é complicado!”

“[...] na pesquisa de bastidores, quando eu converso com os(as) alunos(as), a gente vê o quanto eles contam com essa política, né?”

“[...] Teve um(a) aluno(a) do Curso que eu assessoro pedagogicamente, que “tava” [falando]: “Eles [a CLAE].. eles dão para que eles querem!”.... Eu disse pra ele: "Não seja injusto! Existe toda uma "logística", existe uma equipe que segue os editais... a equipe não faz essa escolha à revelia! Então você tem que analisar o que acontece nos bastidores! Talvez haja alguém mais necessitado que outro, mas será que esse "alguém" mais necessitado que não foi contemplado disponibilizou todos os documentos? Eu digo: "A equipe não pode fazer uma escolha à revelia!" Ela, ela precisa ter todos [os documentos]...”

Depreende-se que muitos(as) estudantes atendem aos requisitos e estariam aptos a ser beneficiados(as) pelos auxílios da PAE, mas que nem todos(as) são contemplados(as), em geral, por questões de contingências de ordem orçamentária e financeira, o que costuma gerar um sentimento de injustiça e desamparo nos estudantes não beneficiados pela PAE, embora haja situações de desclassificação de candidatos à PAE por descumprimento das normas do edital de seleção, falta de comprovação da condição de vulnerabilidade e problemas do envio da documentação requerida.

Todavia, o que parece preponderar e marcar as falas dos membros da CLAE é a percepção de que existe um grande quantitativo de estudantes em condição de vulnerabilidade socioeconômica, mas de que a PAE não consegue alcançar todos os(as) estudantes que estão nessa situação de vulnerabilidade. Essa percepção dos membros da CLAE vai ao encontro de dados apresentados no Relatório de Gestão do IF Baiano - Ano 2019, os quais demonstram que, quanto ao indicador que mede a capacidade de inclusão social da instituição: "Matriculados(as) classificados(as) de acordo com a renda familiar per capita (MRF)”, a renda per capita familiar dos estudantes de I,5 salário até 3,5 salários é igual a 2,06\%, a renda per capita familiar "Não declarada" é igual a 40,46\%, e a renda per capita familiar de o até I,5 salário é igual a 57,47\%. (IF BAIANO, 2020).

Nessa mesma linha, a Plataforma Nilo Peçanha revela que, no que tange ao perfil socioeconômico dos(as) estudantes matriculados(as) no IF Baiano, pode-se observar que II.88o estudantes $(57,47 \%)$ estão em condições de vulnerabilidade social, quando caracterizada a situação de vulnerabilidade pela renda familiar per capita inferior a I,5 salário mínimo, considerando a totalidade das matrículas atendidas no ano de 2019, e 
utilizando a renda familiar per capita como indicador. (PLATAFORMA NILO PEÇANHA, 2020).

Diante dessa difícil situação, a Política de Assistência Estudantil desenvolve um papel primordial para a permanência desses e dessas estudantes na Instituição, o que foi percebido e relatado pelos integrantes da CLAE, conforme pode ser observado nas seguintes falas:

“[...] o único lado positivo nisso é a gente saber que pessoas que estão em condições não tão favoráveis economicamente, estão tendo acesso a estudar no IF Baiano! É, a única coisa positiva é essa, que se estivessem todas, né?... em uma condição econômica interessante, aí significaria que quem estava pertencendo ao local público são pessoas que não deveriam estar nesse local público... "não deveria" talvez seja um pouco pesado, mas é... quem vem de origem humilde entende o que é você querer estudar em um IF..."

“[...] aqui quando a gente percebe que o pessoal tá tendo essa entrada, então é algo gratificante nesse sentido, mas que é uma grande quantidade [de estudantes na condição de vulnerabilidade], é!”

“[...] o que eu posso falar é da experiência do contato com os alunos: que não deixa de ser uma ajuda, não é uma ajuda total, mas é $[. .$.$] muitas vezes é tudo que$ o sujeito tem para contar naquele mês!"

“[...] a gente não pode negar também que não impacta! Às vezes a gente minimiza: “Ah! É pouco!”, é isso... mas antes não tinha nada!”

"Especificamente hoje comprovado, a gente tem cento e oitenta e seis alunos(as), né, que recebem o auxílio emergencial... é um pouco mais de duzentos que recebe o kit alimentício, e temos aí cinquenta que recebe o auxílio digital emergencial.”

"Sabemos que esses auxílios, que é o que a gente está contabilizando, não contempla a todos(as) que precisam..."

“Então acho que... desconfio que a gente tem, pelo menos, cinquenta por cento... sessenta por cento do nosso alunado deve estar em situação de vulnerabilidade, desconfio! Mas isso em dados, a gente não... eu não tenho como comprovar hoje”.

Muito presente [a situação de vulnerabilidade]

"Eu acho que a Assistente Social deve ter dados mais concretos, mas em si tratando dessa vulnerabilidade de até um salário mínimo e meio, a gente deve "tá" nessa faixa aí, eu acho que cinquenta por cento do nosso alunado, aí, ele deve estar com essa renda per capita!"

"Boa parte não, eu acho que não, não [poderia permanecer no Instituto sem o apoio da PAE]! Principalmente do nosso Técnico [Curso Integrado ao Ensino Médio em Agropecuária], se por exemplo retirássemos as refeições, não teríamos condições de... desses alunos, por exemplo, ter que comprar... em tempo integral, eles teriam que pagar alimentação.”

"Então acho que mais de noventa por cento do nosso Médio Integrado [alunos(as) do Curso Integrado ao Ensino Médio em Agropecuária], eles não se manteriam [sem o apoio da PAE]!

"Pela minha experiência, eu acho que noventa por cento dos(das) nossos(as) alunos(as) não teriam condições para pagar café e almoço, para se manter!” 
Eu acho que mais digno seria se a gente tivesse condições, né, de dá amparo a todos que tivesse na questão... na condição de vulnerabilidade socioeconômica!”

Relativa à categoria Percepção da CLAE sobre a relação entre os índices de Evasão e a permanência e êxito estudantil dos beneficiários da PAE, para contextualizar a análise, convém considerar o indicador 'Taxa de Evasão', que mede o percentual de alunos(as) que abandonaram o curso, os(as) que tiveram a matrícula cancelada, e os que se desligaram e se transferiram do Instituto Federal Baiano, o qual mostra que nos anos de 2015, 2016, 2017, 2018 e 2019, o a "TE” foi de 8,14\%, 12,16\%, 25,9\%, 24,6\% e 21\%, respectivamente, embora a meta estipulada pelo IF Baiano tenha sido 8\%. (IFBAIANO, 2020).

Conforme consta no Relatório de Gestão do IF Baiano - Ano 2019 (IFBAIANO, 2020), o indicador Taxa de Evasão (TE), nos últimos quatro anos, ficou acima das metas estabelecidas no Plano de Desenvolvimento Institucional - PDI (IF BAIANO, 2015), o que indica que a quantidade de estudantes que perderam o vínculo com a Instituição, antes da conclusão de seus cursos, foi maior do que a estimada pela Administração, sendo que, nesse ano de 2019, a situação de matrícula com status "desligado" e "abandono" teve um aumento expressivo. Dessa forma, apesar da redução contínua dos três últimos anos, a queda da evasão nos diversos Cursos oferecidos pelo IF Baiano, ainda tem sido lenta, ficando distante de alcançar a meta planejada, de 10\% em 2018 e 8\% em 2019, uma vez que a análise do percentual global de evasão no Instituto, por tipo de curso, revela que os cursos da Formação Inicial e Continuada lideram o escore, seguidos pelos Cursos da Licenciatura e os Cursos Técnicos (ı6,60\%). (IF BAIANO, 2020).

Nesse cenário, os membros da CLAE do IF Baiano, Campus Senhor do Bonfim relataram perceber uma relação entre os índices de evasão escolar e a permanência e êxito estudantil dos beneficiários da PAE:

\footnotetext{
"Então, é importante é muito importante! E, em alguns casos é uma "inspiração" para alguns alunos(as) continuarem no Curso... a necessidades obriga a pessoa.”

“Este é um programa muito importante para a permanência dos(das) alunos(as). Porém há muitos detalhes a ser melhorado [...].

“[...] no papel de observação quanto a isso, eu acho que faz total diferença, principalmente se a gente considera o perfil social da maioria dos(das) nossos(as) estudantes.”

"Então, eu acho que é uma política que... se ela se acaba... tipo, o Instituto se acaba junto com ela!”

“[...] a gente percebe a necessidade do auxílio, né,... pra... e da efetividade nisso em manter o(a) estudante, né?”
} 


\begin{abstract}
"Existem casos de alunos(as)... que esse benefício que eles recebem da Assistência Estudantil, é o que custeia a alimentação de casa!”

“[...] caso eles não tivessem esse auxílio: ou eles teriam que deixar o curso e trabalhar, procurar emprego, né,... ou eles... é... eles iam acabar de todo jeito é evadindo do IF Baiano!”

“[...], esse auxílio é muito importante para eles! É fundamental!”

"Então, assim se a gente pensar nos governos anteriores, nas políticas anteriores, onde os sujeitos não tinham esse auxílio, né? Então, assim.. eu acho que impacta, embora ela não seja o suficiente! Mas não ser suficiente não significa dizer que não tem impacto! Então, eu acho que impacta sim, sendo o objetivo! E, parando para pensar... que outrora já houve uma ausência total de políticas nesse sentido, né?"
\end{abstract}

Observa-se que, para os integrantes da CLAE, a oferta da Assistência Estudantil colabora na diminuição dos índices de evasão e abandono, que os auxílios da PAE do IF Baiano têm servido de incentivo ou inspiração para continuidade dos estudos e para favorecer a democratização do acesso e auxiliar na permanência e no êxito do processo formativo dos discentes contemplados pela PAE.

Nota-se ainda que, embora a Comissão da CLAE não disponha de dados específicos e sistematizados do Campus Senhor do Bonfim relativos à permanência ou à conclusão com êxito por parte dos(das) estudantes beneficiados(as) pela PAE (por falta de um sistema ou

plataforma de gestão de dados), ainda assim comungam da percepção de que a PAE impacta positivamente da vida e desempenho acadêmico dos estudantes beneficiados por essa Política, razão pela qual entendem que esta deve ser incentivada, fortalecida e ampliada, com o fito de alcançar um maior número de estudantes e ajudar a mitigar os efeitos das dificuldades resultantes da pobreza e vulnerabilidade socioeconômica, os quais interferem sobre os índices de evasão e abandono escolar.

\title{
CONSIDERAÇÕES
}

Apresentamos a experiência da realização de pesquisa sobre a Política de Assistência Estudantil, a qual contou com o levantamento de dados e pesquisa de campo, através de GF com os membros da CLAE do Instituto Federal Baiano, Campus Senhor do Bonfim (locus da pesquisa) e da aplicação de questionários destinados aos membros dessa Comissão.

Compreendemos que a pesquisa conseguiu atingir de modo suficiente o seu objetivo geral de investigar, a partir da percepção dos membros da Comissão Local de Assistência Estudantil, em consonância com os indicadores institucionais, em que medida a Política de 
Assistência Estudantil (PAE) no Instituto Federal Baiano, Campus Senhor do Bonfim impacta no desempenho acadêmico dos estudantes beneficiários.

Entretanto, pondera-se que, em que pese ter sido essa experiência de pesquisa profícua, ela não se constitui em um modelo definitivo, absoluto, ou completo quanto à contribuição da assistência estudantil ao acesso, permanência e êxito estudantil, dada as condições sistêmicas prevalecentes no status quo, notadamente quanta às contingências de ordem administrativa, aos fatores relacionados aos reiterados cortes e contenção de recursos da PAE, e ao fato da CLAE não dispor de mais dados localizados e específicos do Campus Senhor do Bonfim relativos à permanência ou à conclusão com êxito por parte dos(das) estudantes beneficiados(as) pela PAE ao longo de suas trajetórias, embora deva-se registrar que os membros da CLAE do IF Baiano, Campus Senhor do Bonfim, relataram perceber uma relação entre os índices de evasão escolar e a permanência e êxito estudantil dos(das) beneficiários(as) da PAE, pois expuseram que compreendem que a oferta da Assistência Estudantil colabora na diminuição desses índices de evasão e abandono, na medida em que os auxílios da PAE do IF Baiano têm servido de incentivo ou inspiração para continuidade dos estudos, e consequentemente para favorecer a democratização do acesso, permanência e o êxito no processo formativo dos discentes beneficiados.

Faz-se necessária a realização de trabalhos futuros, especialmente quanto à permanência e à conclusão com êxito dos(das) estudantes beneficiados(as) pela PAE ao longo de seus percursos acadêmicos e suas trajetórias, e há a necessidade de se pesquisar sobre a condição dos(das) egressos(as) que foram anteriormente beneficiados(as) pela PAE, além da necessidade de realização de estudos que tragam um detalhamento e constatação relativa à 'finalização com êxito/sucesso' e 'finalização sem êxito/insucesso', a partir dos conceitos e dados extraídos do Sistema Nacional de Informações da Educação Profissional e Tecnológica (Sistec).

Compreendemos que o estudo apresentado nesta pesquisa pode servir de referencial, na medida em que demonstra o impacto positivo da Política de Assistência Estudantil na vida dos(das) estudantes, a partir da percepção dos membros da CLAE do IF Baiano, Campus Senhor do Bonfim, e dos dados e indicadores institucionais expostos, uma vez que a PAE ajuda a viabilizar as condições necessárias e os meios materiais básicos para o fruição mais plena do ambiente escolar, através da concessão dos diversos auxílios que 
compõem essa política, como moradia, transporte, creche, auxílio permanência, cópia e impressão, uniforme, material acadêmico e alimentação - dentre outros, o que tende a ajudar a diminuir os índices de evasão do Instituto Federal Baiano.

Nessa linha, por exemplo, a Plataforma Nilo Peçanha (BRASIL, 2020) apresenta dados relevantes referentes à taxa de evasão no Curso Técnico de Nível Médio Integrado em Agropecuária, Campus Senhor do Bonfim, principal curso oferecido pela instituição. O dado mais atualizado dessa Plataforma revela que é de $16,5 \%$ a taxa de evasão escolar, o que se entende como um percentual alto, e, portanto, a ser diminuído, embora retrate um aspecto comum da realidade da EPT no Brasil, que é a ainda frequente e persistente problemática da evasão escolar.

Dessa forma, entende-se que o aperfeiçoamento e fortalecimento da PAE no âmbito do IF Baiano, Campus Senhor do Bonfim, na proporção que possibilita aos(às) estudantes em vulnerabilidade socioeconômica os meios materiais para o seu bem estar biopsicossocial, e permanência e êxito nas atividades acadêmicas, pode-se constituir também em um importante fator para o enfrentamento do fenômeno da evasão escolar. Ressalta-se aqui, portanto, a importância da assistência estudantil no desideratum de superação dos obstáculos e impedimentos ao desempenho acadêmico de qualidade, e enquanto fator de minimização do percentual de evasão escolar.

\section{REFERÊNCIAS}

BARDIN, Laurence. Análise de conteúdo (Tradução de L. de A. Rego e A. Pinheiro, Trads.). Lisboa: Edições 70, 2006. (Obra original publicada em 1977).

BATESON, Gregory. Steps to a ecology of mind: collected in anthropology, psychiatry, evolution, and epistemology. Chicago: University of Chicago Press, 2000.

BRASIL. Constituição da República Federativa do Brasil de 1988. Brasília, DF, Presidência da República. Disponível em:http://www.planalto.gov.br/ccivil_03/constituicao..htm. Acesso em: Io ago. 2021.

. Decreto no 7.234, de 19 de julho de 2010. Dispõe sobre o Programa Nacional de Assistência Estudantil - PNAES. Disponível em: http://www.planalto.gov.br/ccivil_03 em: 05 jul. 2021.

Lei no Ir.892, de 29 de dezembro de 2008. Institui a Rede Federal de Educação Profissional, Científica e Tecnológica, cria os Institutos Federais de Educação, Ciência e Tecnologia, e dá outras providências. D.O.U. Seção I, de 30 de dezembro de 2008. Brasília, 
DF, 2008. Disponível em: http://www.planalto.gov.br/ccivil_03/_ato2007-2010/2008/lei/. Acesso em: 04 ago. 2021.

CARLINI-COTRIM, Beatriz. Potencialidades da técnica qualitativa grupo focal em investigações sobre abuso de substâncias. Rev. Saúde Pública, São Paulo, v. 30, n. 3, p. 28593, 1996.

CONSELHO NACIONAL DE SAÚDE. Resolução no 466/2012. Disponível em: http://bvsms.saude.gov.br/bvs/saudelegis/cns/2013/reso466_12_12_2012.html. Acesso em: 02 jul. 2021.

CONSELHO NACIONAL DE SAÚDE. Resolução no 510/2016. Disponível em: http://conselho.saude.gov.br/resolucoes/2016/Reso5io.pdf. Acesso em: 02 jul. 202I.

GODOY, Arilda S. Pesquisa qualitativa: tipos fundamentais. Revista de Administração de Empresas, v. 35, n. 4, 1995.

GOMES, Maria E. S.; BARBOSA, E. F. A técnica educativa de grupos focais para obtenção de dados qualitativos. Educativa, 1999. Disponível em: www.dppg.cefetmg.br/mtp/Tecnicade GruposFocaisdoc. Acesso: Io ago. 202I.

Plano de Desenvolvimento Institucional (PDI 2015-2019). Disponível em: http://ifbaiano.edu.br/portal/wp-content/uploads/2015/12/pdi-2015-2019-versão 2018.pdf. Acesso em: or ago. 2021.

Política de Assistência Estudantil. Resolução no or, de 29 de janeiro de 2019. Disponível em:http://www.ifbaiano.edu.br/unidades/itapetinga/files/20II/o5/ResoluçãooI-2019-Aprova-Pol\%02530-2018.42.pdf. Acesso em: io jul 2021.

Resolução no 78/2020 - OS-CONSUP/IFBAIANO, de 29 de agosto de 2020: Aprova o Relatório de Gestão/2019 do IF Baiano. Anexo. Disponível em: https://ifbaiano.edu.br/portal/wp-content/uploads/2020/o9/Resolu\% $\mathrm{C}_{3} \% \mathrm{~A}_{7 \%} \% \mathrm{C}_{3} \% \mathrm{~A}_{30-}$ 78_2020-OS-CONSUP_IFBAIANO.pdf. Acesso em: or ago. 2021.

KOWALSKI, A. V. Os (des)caminhos da política de assistência estudantil e o desafio na garantia de direitos. Tese (Doutorado em Serviço Social) - Pontifícia Universidade Católica do Rio Grande do Sul, Porto Alegre, 2012. Disponível em: http://repositorio.pucrs.br/dspace/handle/ı0923/5137. Acesso em: I4 ago. 2020.

PLATAFORMA NILO PEÇANHA, [2020]. Disponível em: http://plataformanilopecanha.mec.gov.br/. Acesso em: 09 jul. 2021.

RAMALHO, Ludmila Eleonora G. Abordagem avaliativa da política de assistência estudantil em uma instituição de ensino profissional. Dissertação (Mestrado Profissional em Gestão e Avaliação da Educação Pública) - Universidade Federal de Juiz de Fora, Juiz 
de Fora-MG, 2013, I64 p. Disponível em:https://repositorio.ufjf.br/jspui/bitstream/ mesramalho.pdf. Acesso em: I2 jul. 2021.

SKYPE. [2020]. Disponível em: https://www.skype.com/pt-br/get-skype/. Acesso em: 07 jul. 2021.

THOMPSON, John B. Ideologia e cultura moderna: teoria social crítica na era dos meios de comunicação de massa. 2. ed. (Grupo de Estudos sobre Ideologia, Comunicação e Representações Sociais da Pós-Graduação do Instituto de Psicologia da PURCS, Trad.). Rio de Janeiro: Vozes, 1995. (Obra original publicada em 1990).

TRIVIÑOS, Augusto Nibaldo S. Introdução à pesquisa em ciências sociais: a pesquisa qualitativa em educação. São Paulo: Atlas, 1987. 